\title{
EDITORIAL
}

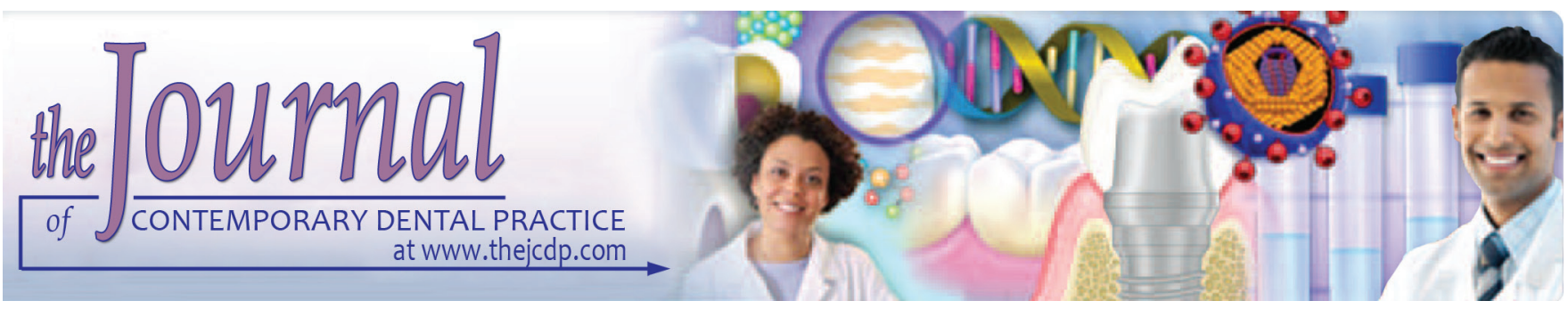

\section{Junk DNA: Prospects for Oral Cancer Research}

\author{
${ }^{1}$ Gargi S Sarode, ${ }^{2}$ Sachin C Sarode, ${ }^{3}$ Shankargouda Patil, ${ }^{4}$ Rahul Anand
}

How to cite this article: Sarode GS, Sarode SC, Patil S, Anand R. Junk DNA: Prospects for Oral Cancer Research. J Contemp Dent Pract 2016;17(3):177-178.

\section{Source of support: Nil}

\section{Conflict of interest: None}

About $98 \%$ of human genes are transcribed into noncoding ribonucleic acid (RNA), which is known by the name of "junk DNA." Unlike its name, it has been proved by now that junk deoxyribonucleic acid (DNA) can have some functional activities. These fragments of nonfunctional DNA have evolved by undergoing exaptation. Researchers have identified a fragment of noncoding RNA transcribed from this stretch of junk DNA that does not code for any protein. However, a controversy still mongers over this noncoding RNA, whether it is just a "noise" or exists to serve any cellular function. ${ }^{1}$

This noncoding RNA plays a role in stopping the malignant transformation of the normal cells. It helps to maintain the cellular health through two main mechanisms: (1) by regulating DIRAS3 levels, an important neighboring gene involved in cell replication; and (2) by suppressing a network of genes responsible for changing the shape of the cells and preparing them for metastasis. ${ }^{1}$

DIRAS3 (ARHI/NOEY2) is a tumor suppressor gene. It encodes a small GTPase with $60 \%$ homology to

\footnotetext{
${ }^{1,2,4}$ Department of Oral Pathology and Microbiology, DY Patil Dental College and Hospital, DY Patil Vidyapeeth, Pune Maharashtra, India

${ }^{3}$ Department of Preventive Dental Sciences, College of Dentistry, Jazan University, Jazan, Kingdom of Saudi Arabia

Corresponding Author: Gargi S Sarode, Associate Professor Department of Oral Pathology and Microbiology, DY Patil Dental College and Hospital, DY Patil Vidyapeeth, SantTukaram Nagar, Pimpri, Pune-411018, Maharashtra, India, Phone: +919823871462, e-mail: gargi14@gmail.com
}

Ras and Rap. It is responsible for the regulation of cell growth through controlling the expression of the cyclins and cyclin-dependent kinase inhibitors. It also regulates various steps in autophagy, such as induction and membrane elongation. It is absent or expressed at lower levels along with allelic loss. It is found to be responsible for promotion of hypermethylation in ovarian, breast, liver, and other various malignancies. ${ }^{2}$

Zhang et $\mathrm{al}^{3}$ performed methylated DNA immunoprecipitation coupled with methylation microarray analysis to screen for aberrantly methylated genes in normal and cancerous tongue tissue. A total of 1269 hypermethylated CpG sites covering 330 genes and 1385 hypomethylated CpG sites covering 321 genes were found in lesional tissue, compared with the adjacent normal mucosa. Three genes (BCL2L14,CDCP1, and DIRAS3) were tested by reverse transcription polymerase chain reaction (RTPCR), and as a result, marked upregulation of BCL2L14 and CDCP1 and downregulation of DIRAS3 was found.

Similarly, Stojic et al ${ }^{1}$ identified a strand of noncoding RNA, known as GNG12-AS1. It is seen to be responsible for prevention of the growth switch getting stuck, and thus, as a result, it suppresses metastasis of the malignant lesion. The specific genomic region where this noncoding RNA is located gets affected in breast cancer, and thus, the control is removed and metastasis can occur.

Oral cancer is unique in many aspects from other carcinomas of the body. ${ }^{4}$ Even the tumor cells react differently to chemotherapeutic drugs due to this uniqueness. ${ }^{5}$ Thus, the findings of the above preliminary studies can be used to understand how other noncoding RNAs function and their role in oral carcinogenesis and metastasis. More elaborative gene-specific studies are required to be carried out in future to encode various unidentified junk DNAs involved in oral cancer.

Viral oncogenesis is a well-known phenomenon and an established fact in carcinogenesis process. In 
oral cancer, human papilloma virus 16 and 18 are considered to be oncogenic, which showed interactions with different signaling pathways. Such interactions and modulation of signaling pathways often complicate the process of carcinogenesis. ${ }^{6,7}$ We strongly believe that HPV 16 and 18 have the potential to interact with junk DNAs, thus facilitating carcinogenesis. Understanding of such interactions is important for future targeted drug development strategies in oral cancer.

Inflammation now has been considered as one of the hallmarks of carcinogenesis. ${ }^{8}$ Oral cancer is the perfect example of inflammation-mediated carcinogenesis and researchers are trying to establish targeted drug therapy in this regard. ${ }^{9}$ We believe that the role of junk DNA at transcriptional level in facilitating tumorigenic inflammation would be an interesting area of future research. This will help in better understanding of "inflammation mediated carcinogenesis" mechanism. Similarly, stress has also been regarded as one of the carcinogens, as it promotes and accelerates the pro-tumorigenic environment. ${ }^{10,11}$ Future studies should also be directed toward stress in oral cancer patients and junk DNA profile.

Predicting malignant transformation of potentially malignant disorders has always been a challenge to the clinicians and researchers. ${ }^{12}$ Molecular studies have reported upregulation and downregulation of certain sets of biomarkers, but still uncertainty surrounds the prediction of malignant transformation. Moreover, there are diversified groups of disorders that fall under premalignant category, which makes biomarker profiling for such prediction more complicated. ${ }^{13}$ It has been observed in the literature that junk DNA has not yet been investigated in this regard. We believe that future research on this aspect could throw some light on this, which will help in identification of high-risk lesions and their early management. ${ }^{14}$

We would also like to suggest a need of a microarray membrane by which multiple junk DNAs can be studied simultaneously. This will help in developing more accurate junk DNA related biomarkers for cell proliferation, migration, invasion, survival, and metastasis. Thus, unveiling this relatively unexplored aspect of oral cancer will definitely help in developing potential therapies in future.

\section{REFERENCES}

1. Stojic L, Niemczyk M, Orjalo A, Ito Y, Elisabeth AMR, UribeLewis S, Joseph N, Weston S, Menon S, Odom DT, et al. Transcriptional silencing of long noncoding RNA GNG12-AS1 uncouples its transcriptional and product-related functions. Nat Commun 2016 Feb;7:10406.

2. Baljuls A, Beck M, Oenel A, Robubi A, Kroschewski R, Hekman M, Rudel T, Rapp UR. The tumor suppressor DiRas3 forms a complex with H-Ras and C-RAF proteins and regulates localization, dimerization, and kinase activity of C-RAF. J Biol Chem 2012 Jun 29;287(27):23128-23140.

3. Zhang S, Feng X, Shi L, Gong C, He Z, Wu H, Ling T. Genomewide analysis of DNA methylation in tongue squamous cell carcinoma. Oncol Rep 2013 May;29(5):1819-1826.

4. Sarode SC, Sarode GS. Is oral cancer unique in terms of chemotherapeutic and targeted drug metabolism? J Oral Maxillofac Surg 2015 Jan;73(1):4-6.

5. Sarode GS, Sarode SC, Patil S. Accept and respect the uniqueness of oral cancer. World J Dent 2014;5(4):v-vi.

6. Sarode GS, Sarode SC. E6 oncoprotein interaction with paxillin and FAK. Oral Oncol 2014 Apr;50(4):e17.

7. Sarode SC, More P, Sarode GS. E6 and E7 interactions with micro-RNA. Oral Oncol 2014 Aug;50(8):e46-e47.

8. Sarode SC, Sarode GS, Patil A. Therapeutic aspects of the inflammation mediated oral carcinogenesis. Oral Oncol 2014 Apr;50(4):e13-e14.

9. Sarode GS, Sarode SC, Patil A, Anand R, Patil SG, Rao RS, Augustine D. Inflammation and oral cancer: an update review on targeted therapies. J Contemp Dent Pract 2015 Jul1;16(7):595-602.

10. Anand R, Sarode GS, Sarode SC. Chronic stress and oral cancer research: Disregarded aspects in animal model studies. Oral Oncol 2016 Mar;54:e5-e6.

11. Sarode GS, Sarode SC, Anand R, Patil S, Rao R, Augustine D. Psychological intervention in head and neck cancer from molecular standpoint. World J Dent 2014;5:249-250.

12. Sarode SC, Sarode GS, Tupkari JV. Oral potentially malignant disorders: précising the definition. Oral Oncol 2012 Sep; 48(9):759-760.

13. Sarode SC, Sarode GS, Karmarkar S, Tupkari JV. A new classification for potentially malignant disorders of the oral cavity. Oral Oncol 2011 Sep;47(9):920-921.

14. Sarode SC, Sarode GS, Tupkari JV. Oral potentially malignant disorders: a proposal for terminology and definition with review of literature. J Oral Maxillofac Pathol 2014 Sep;18(Suppl 1):S77-S80. 